\title{
Paradigm shifts for Industry 4.0 and the impact on society
}

\author{
Joseph Falzon \\ University College, Malta College of Arts, Science and Technology, MALTA
}

\begin{abstract}
Developments in information and communication technologies (ICT) continuously lead towards shifting paradigms in industry. Achievements in multidisciplinary areas underpinned by technical advancements and knowledge transfer consequently demand societal changes. As industry targets are mainly driven by motivation for innovation and economic growth, the way how progress is being disseminated within the layers of social texture and the social contexts are often queried. This paper develops insights of the European Commission (EC) and European member states in pursuing innovation policy for Industry 4.0. Perspectives on policy structures for innovations in multi-level governance addressing social justice, social innovations and social cohesion by the Organisation for Economic Co-operation and Development $(\mathrm{OECD})$ and the Council of Europe $(\mathrm{CoE})$ for Industry 4.0 are also reviewed.
\end{abstract}

Keywords: Economic growth, Industry 4.0; Innovation, Knowledge transfer, Social cohesion. 